\title{
System Investigations of the SpaceLiner Concept in FAST20XX
}

\author{
Martin Sippel, Arnold van Foreest, Carola Bauer \\ Space Launcher Systems Analysis (SART), DLR, Bremen, Germany \\ Francesco Cremaschi \\ Astos Solutions GmbH, Stuttgart, Germany
}

\begin{abstract}
DLR's launcher systems analysis division has proposed a visionary, extremely fast passenger transportation concept reaching the edges of space based on rocket propulsion. The paper describes the recent technical progress achieved in the SpaceLiner configuration. The revolutionary ultrafast transport is now under investigation in the EU-funded study FAST20XX (Future high-Altitude high-Speed Transport 20XX) set off in December 2009. The focus of the paper is on all system aspects of the preliminary design including its flight performance impact on design choices. A major new result is the replacement of the original skipping trajectory by a smooth glide obtained in system optimizations.
\end{abstract}

Subscripts, Abbreviations

$\begin{array}{ll}\text { AoA } & \text { angle of attack } \\ \text { CAD } & \text { computer aided design } \\ \text { GLOW } & \text { Gross Lift-Off Mass } \\ \text { LH2 } & \text { Liquid Hydrogen } \\ \text { LOX } & \text { Liquid Oxygen } \\ \text { MECO } & \text { Main Engine Cut Off } \\ \text { RLV } & \text { Reusable Launch Vehicle } \\ \text { TPS } & \text { Thermal Protection System } \\ \text { TRL } & \text { Technology Readiness Level }\end{array}$

\section{Introduction}

A strategic vision has been proposed by DLR which ultimately has the potential to enable sustainable low-cost space transportation to orbit. The baseline idea is simple and quite conventional: Strongly surging the number of launches per year and hence dramatically shrinking manufacturing and operating cost of launcher hardware. The obvious challenge of the vision is to identify the very application creating this new, large-size market. All recent assessments of the launch business are sobering. Nevertheless a market, well beyond the recent assessment, could be created if the conventional thinking of what rocket propelled vehicles are to be used for is exceeded.

Ultra long distance travel from one major business center of the world to another major agglomeration on earth is a huge and mature market. Since the termination of Concorde operation, intercontinental travel is restricted to lowspeed, subsonic, elongated multi-hour flight. An interesting alternative to air-breathing hypersonic passenger airliners in the field of future high-speed intercontinental passenger transport vehicles might be a rocket-propelled, suborbital craft. Such a new kind of 'space tourism' based on a two stage RLV has been proposed by DLR under the name SpaceLiner [1]. Ultra long-haul distances like Europe - Australia could be flown in 90 minutes. Another interesting intercontinental destination between Europe and North-West America could be reduced to flight times of about one hour [6].

Ultra fast transportation far in excess of supersonic and even potential hypersonic airplanes is definitely a fundamental new application for launch vehicles. Even in the case that only a very small portion of the airline's upper business travel segment could be tapped by a rocket-propelled intercontinental passenger transport, the resulting launch rates per year would be far in excess of any other credible scenario. By no more than partially tapping the huge intercontinental travel and tourist market, production rates of RLVs and their rocket engines could increase hundredfold which is out of reach for all other known earth-orbit space transportation. The fast intercontinental travel space tourism, not only attracting the leisure market, would, as a byproduct, also enable to considerably reduce the cost of space transportation to orbit. 


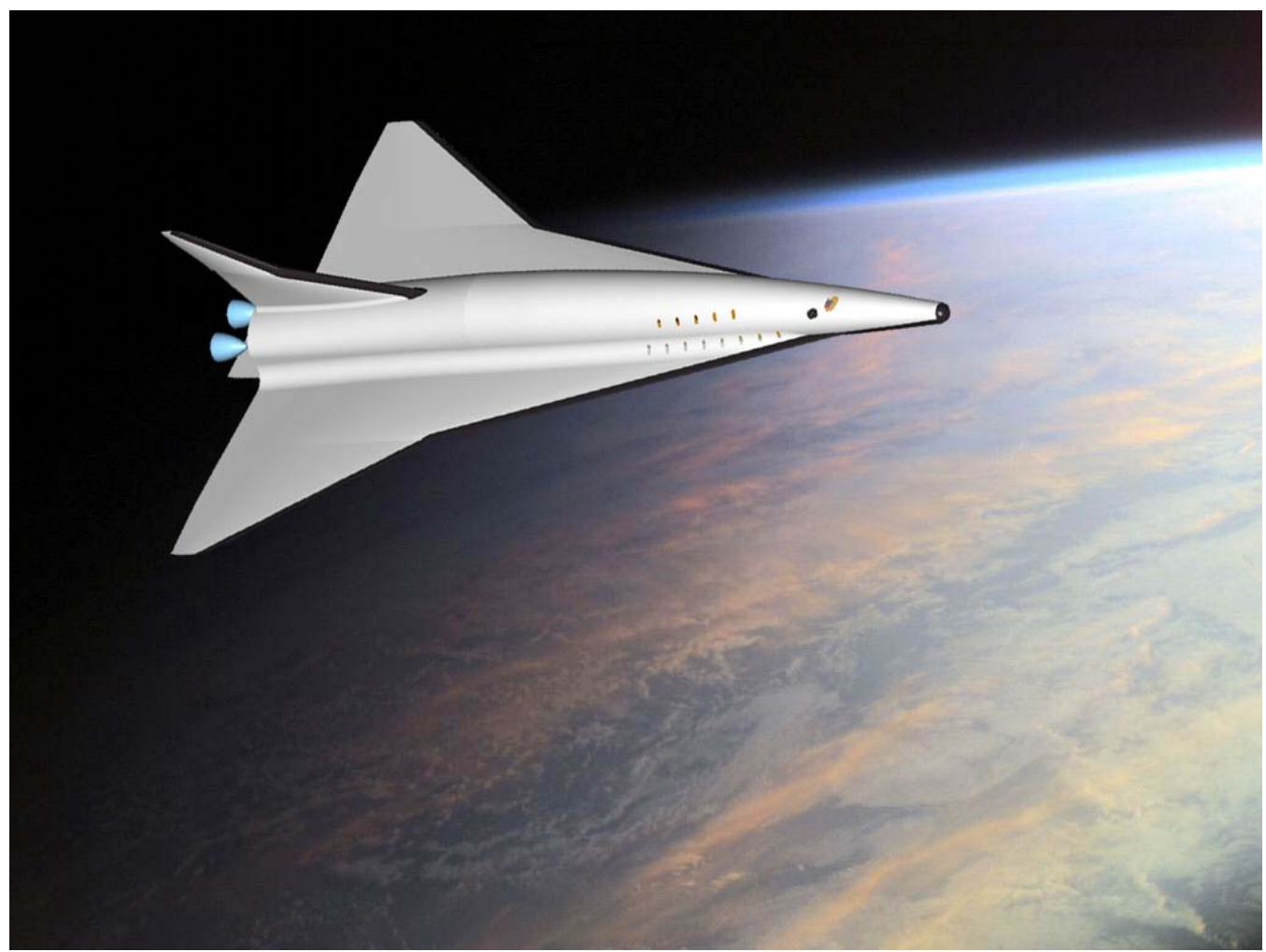

Figure 1: The SpaceLiner vision of a rocket-propelled intercontinental passenger transport, shown here in an artist's impression of configuration 2 , could push spaceflight further than any other credible scenario

An interesting alternative in the field of high-speed intercontinental passenger transport vehicles might be a rocketpropelled, suborbital craft. The functionality of rocket propulsion is a proven technology since decades and their performance characteristics are well known. Furthermore, a rocket powered RLV-concept like the SpaceLiner is more attractive because the flight durations are two to three times lower than those of even the most advanced airbreathing systems. It is to be recognized that travel times of any airliner are not identical to flight times. Additional times for commuting to the airport hub which offers the long-distance flight, check-in, security-check and those to be accounted for waiting and transfer are to be considered. A preliminary estimation of the expected travel time for a SpaceLiner passenger shows approximately 5 to 6 hours for ultra-long distances. This result corresponds to a reduction in the actual time needed for travelling between at least $75 \%$ and $80 \%$ compared to conventional subsonic airliner operation: Those reach about 23 hours for non-stop service and typically about 30 hours for single stop Europe-Australia flights.

In contrast to the first generation of SST, thus a substantial advantage in travel times and hence improved business case can be expected. Potentially interesting destinations and their respective flight distances if following the orthodrome are listed in [8]. Airbus already recognized the interesting long-term potential of ultra-fast rocketpowered passenger planes [9]. A first assessment of the SpaceLiner's potential business case is described in the references 1, 2, and 5. A more detailed market analyses is currently ongoing in order to find out who might be interested in using the SpaceLiner in the future for travelling.

The environmental impact of the LOX-LH2 propelled SpaceLiner is relatively benign and seems to be much less critical than for airbreathing concepts. The rocket concept is releasing even less exhaust gases into the atmosphere than today's commercial airliners because the engines do not burn the air. Most of the flight trajectory is at a much higher altitude than for the airbreathing vehicles considerably reducing the noise impact on ground. Nevertheless, the launch has to most likely be performed off-shore or in remote, unpopulated areas due to expected noise at liftoff. Consequently decoupling of the launch and landing site will create some logistical challenges. A first assessment of the logistics is described in [7]. 


\section{General Description of SpaceLiner concept}

\section{A. Status of Previous Technical Development}

First proposed in 2005 [1], the SpaceLiner is under constant development and descriptions of some major updates have been published since then $[2,3,4,6]$.

The general baseline design concept consists of a fully reusable booster and orbiter (including the passengers) arranged in parallel. All engines should work from lift-off until MECO. A propellant crossfeed from the booster to the orbiter is foreseen up to separation to reduce the overall size of the orbiter stage. During the SpaceLiner's design evolution the expansion ratios of the booster and orbiter engines are adapted to their respective optimums, while mass flow, turbo-machinery, and combustion chamber remain identical. Fuel rich staged combustion cycle engines with a moderate $16 \mathrm{MPa}$ chamber pressure, $384.5 \mathrm{~kg} / \mathrm{s}$ mass flow, and $437.6 \mathrm{~s}$ (booster) / $448 \mathrm{~s}$ (orbiter) $\mathrm{I}_{\mathrm{sp}}$ in vacuum are assumed for the propulsion system. These engine performance data are not overly ambitious and have already been exceeded by existing engines like SSME or RD-0120. However, the ambitious goal of a passenger rocket is to considerably enhance reliability and reusability of the engines beyond the current state of the art.

Different flight options exist in principle after MECO. The atmospheric skipping looked most attractive considering achievable flight range, launch mass, and mechanical loads. However, the stagnation point heat flux might exceed 4 $\mathrm{MW} / \mathrm{m}^{2}$ (2.1 MW/ $\mathrm{m}^{2}$ in nose region) for a short time because the orbiter has to fly with a Mach number of almost 20 at altitudes below $50 \mathrm{~km}$ (see Figure 2). According to a preliminary estimation the adiabatic equilibrium temperature might exceed $3000 \mathrm{~K}$ in the nose and leading edge regions.. New approaches for the structural materials and thermal protection including advanced active cooling have to be implemented. Some promising design options are outlined in [6] and a first engineering estimation on the amount of cooling fluid required during skip reentry after the orbiter's MECO.
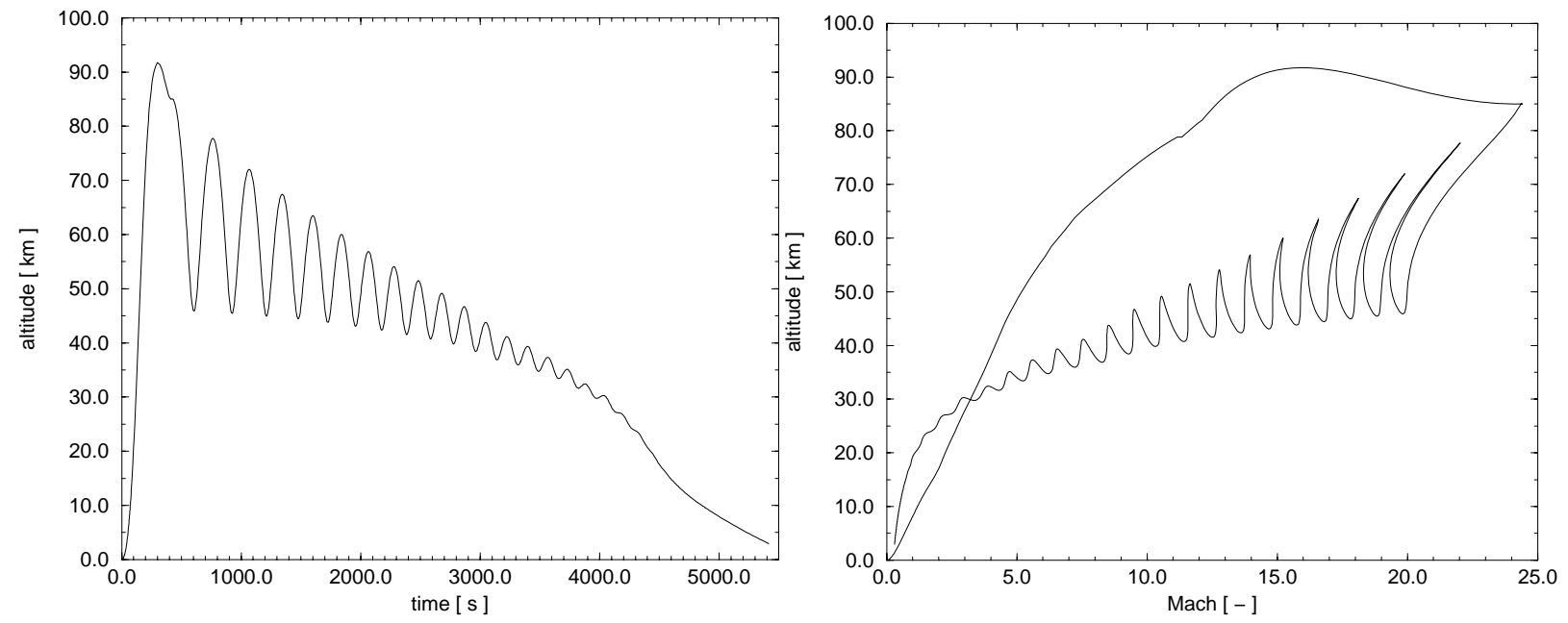

Figure 2: Altitude as function of time and of Mach number of the old SpaceLiner2 Australia-Europe reference trajectory [6]

\section{B. Status and Direction of FAST20XX Technical Development}

Within the EU-funded FAST20XX (Future high-Altitude high-Speed Transport 20XX) project the next iteration loop has been initiated. The multinational collaborative research project FAST20XX aims at providing a sound technological foundation for the industrial introduction of advanced high-altitude high-speed transportation in the medium term and in the longer term (SpaceLiner application) [10]. Note that no detailed vehicle design is planned in the study but the mastering of technologies required for any later development. The identified critical technologies are investigated in depth by developing and applying dedicated analytical, numerical and experimental tools, while the legal/regulatory issues are discussed with government or international authorities.

The high-energy concept SpaceLiner is intended to achieve a step change in ultra-fast long-haul passenger and freight transport. Although the basic performance data of the vertically launching and horizontally landing two-stage 
vehicle are undisputable, the eventual commercial realization is facing quite a lot of technical and operational challenges [11]. Some of these challenges characteristic for any high-energy transportation are addressed in the FAST20XX project. An overview on all SpaceLiner related activities has been published in [11] and recently achieved progress in all disciplines of the study is presented in [20].

The system analyses work package in FAST20XX, in focus of this paper, is addressing the following subjects:

- Definition of the mission requirements for an ultrafast passenger transport (e.g. limits on acceleration during takeoff and descent, requirements on reusability and propulsion subsystem, safety issues etc).

- Establishment of a preliminary aerodynamic database in the hypersonic flight regime.

- Analysis of the flight profile and nominal flight trajectories for an ultrafast passenger transport.

- Sensitivity of vehicle and trajectory with respect to parameters which are of particular interest for the concept of this vehicle (e.g. L/D, wingload).

- Assessment of safeguard issues, crew safety aspects, including abort mission scenarios and associated requirements. The vehicle is designed for commercial passenger transportation. Therefore safety is of crucial importance. Safety systems and possible high risk flight phases are defined.

- A system of load cases has been generated and a first set of resp. loads for nominal and offnominal conditions documented [13].

- Concept trade-off studies: Different vehicle concepts have been studied (e.g. different geometries have been investigated, to see the effect of geometry on aerodynamic heating, maximum obtainable range, weight, etc.) Also, apart from the LOX-Hydrogen rocket engines, LOXKerosene engines for application on the booster stage have been investigated. An overview description has been published in [12].

- Preliminary definition of SpaceLiner subsystems like:

- Rescue subsystem (see brief description in [12])

- Passenger cabin subsystem

- Propulsion and propellant supply subsystem

- Active cooling subsystem and passive TPS (see section "Thermal protection sizing" below!)

- CAD model establishment.

- Calculation of SpaceLiner masses and centre-of-gravity. After integration of the subsystems, the new COG of the vehicle is calculated and it is checked if the vehicle is trimable in nominal and off-nominal flight conditions (see the section "Aerodynamic Flap Selection Driven by NonNominal Flight Conditions” below!).

- Cost assessment for development and operation will be established.

Different configurations in terms of propellant combinations, staging, aerodynamic shapes, and structural architectures have been analyzed. A subsequent configuration numbering has been established for all those types investigated in sufficient level of detail. The genealogy of the different SpaceLiner versions is shown in Figure 3. The box is marking the configuration trade-offs performed in FAST20XX.

These configuration studies support the definition of the next reference configuration already dubbed "SpaceLiner7". The level of engineering detail of the traded configurations is not exactly the same as for the previous reference SpaceLiner2 type. E.g. full CAD models have not always been generated. However, obtained data of the interim research configurations 3, 4, 5, and 6 are at sufficiently high quality because they have been iteratively sized with careful scaling of the reference mass break-down, preliminary aerodynamic sizing and always trajectory optimization. An overview on these configurations can be found in [12].

\section{Recent Advancements achieved in FAST20XX}

\section{Sophisticated Trajectory Optimization combined with Vehicle Design Optimization}

A new detailed trajectory optimization under the consideration of all relevant mission constraints and objectives is performed for the SpaceLiner4 configuration using the AeroSpace Trajectory Optimisation Software ASTOS [14]. 


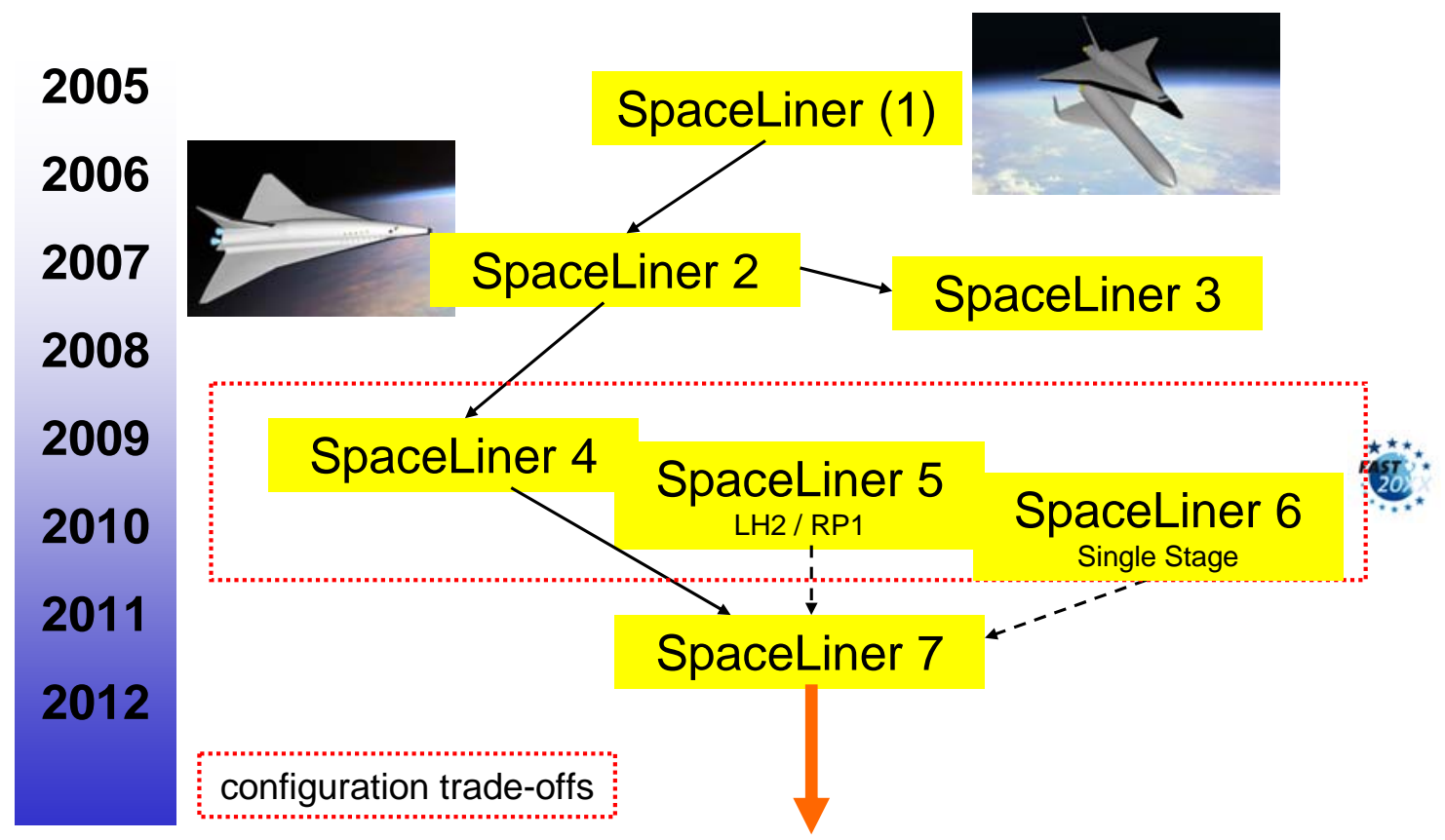

Figure 3: Evolution of the SpaceLiner concept

Astos Solutions GmbH offers a variety of optimization and simulation tools: ASTOS, GESOP, POINT, GAMAG, VESTA et al.. ASTOS is an aerospace optimization tool for launcher and reentry missions. It solves aerospace problems in a fraction of the time needed in comparison to other software available. The completely data driven interface, the automatic initial guesses and the intuitive graphical user interface makes this possible. For more than 20 years ASTOS has been extensively used in several successful missions; among them Hopper, ATV, Ariane 5, VEGA, IXV, X38, and Expert.

\section{Spaceliner (SL) model creation}

The SpaceLiner4 (configuration 2010 [12]) data have been inserted in the ASTOS Model Browser [14, 15] in particular the booster and orbiter components together with the respective propulsion models. Different aerodynamics models have been considered to characterize the vehicle configuration: orbiter and booster attached during early ascent and subsequently the separated orbiter. The Earth is modeled as a rotational ellipse including the $\mathrm{J} 2$ gravitational effect. When not otherwise specified (sensitivity on atmospheric effect) a US standard 76 model has been selected for the atmosphere [16]. Several constraints are present in the mission; some are related to the vehicle physics (e.g. max loads, heat-flux) some to the vehicle controllability (e.g. pitch rate, control profile smoothness). The mission is composed by several phases: vertical takeoff, pitch over, gravity turn during the combined booster and orbiter burn, optimized pitch and yaw control during the orbiter only burn following separation, deceleration glide (“cruise”) phase till $40 \mathrm{~km}$ altitude, and final descent till ground.

The Table 1 gives a short overview of the mission phases and constraints for the Spaceliner vehicle. The reference trajectory has been computed considering the coordinates of Sydney as initial state and the coordinates of Amsterdam as target position.

\section{Mission selection}

Among the various trajectories of interest, some technical aspects are considered in order to identify the most demanding one. Using the mission range as a criteria, the connection between West Europe and Australia (Sydney) is the longest route. In order to select the direction, the effect of the surface rotation of the Earth is considered: this effect is positive for all the trajectories flying "towards East". As result of the selection process, Sydney-West Europe (SWE) is identified as the most demanding mission and thus has always been used as the SpaceLiner's design reference mission. Therefore, this case is also selected for the ASTOS primary optimization process. 
Table 1: Overview of flight phases and their constraints during ASTOS optimization

\begin{tabular}{|c|c|c|c|c|c|}
\hline Phase & Duration & Constraint & Evaluation & Value & Remark \\
\hline $\begin{array}{l}\text { Vertical ascent with booster and } \\
\text { orbiter engines }\end{array}$ & $14.5 \mathrm{~s}$ & Altitude & Phase end & $>80 \mathrm{~m}$ & Launchpad clearance \\
\hline Pitch over maneuver & $8.9 \mathrm{~s}$ & Pitch rate & During the phase & $<1.5 \% \mathrm{~s}$ & Max pitch rate \\
\hline $\begin{array}{l}\text { Gravity turn ascent with booster and } \\
\text { orbiter engines }\end{array}$ & $188.1 \mathrm{~s}$ & Axial load & $\begin{array}{l}\text { During the phase and } \\
\text { phase end }\end{array}$ & $<2.5$ & $\begin{array}{l}\text { Throttle control to avoid } \\
\text { constraint violation }\end{array}$ \\
\hline $\begin{array}{l}\text { Orbiter ascent with optimized pitch } \\
\text { profile }\end{array}$ & $272.0 \mathrm{~s}$ & Axial load & $\begin{array}{l}\text { During the phase and } \\
\text { phase end }\end{array}$ & $<2.5$ & $\begin{array}{l}\text { Throttle control to avoid } \\
\text { constraint violation }\end{array}$ \\
\hline \multirow[t]{2}{*}{$\begin{array}{l}\text { "Cruise” with high heat flux and } \\
\text { optimized bank angle }\end{array}$} & \multirow[t]{2}{*}{$\sim 1500 \mathrm{~s}$} & Heat flux & During the phase & $\begin{array}{l}<1050 \\
\mathrm{~kW} / \mathrm{m}^{2}\end{array}$ & $\begin{array}{l}\text { Limit from the Pareto } \\
\text { optimization }\end{array}$ \\
\hline & & Normal load & During the phase & $\begin{array}{l}>-1.5 \\
<1.5\end{array}$ & Passenger comfort constraint \\
\hline \multirow[t]{3}{*}{$\begin{array}{l}\text { Cruise and descent to Amsterdam } \\
\text { with optimized bank angle }\end{array}$} & \multirow[t]{3}{*}{$\sim 3350 \mathrm{~s}$} & Normal load & During the phase & $\begin{array}{l}>-1.5 \\
<1.5\end{array}$ & Passenger comfort constraint \\
\hline & & Altitude & Phase end & $<3 \mathrm{~km}$ & \\
\hline & & \begin{tabular}{|l} 
Target \\
Distance
\end{tabular} & Phase end & $<10 \mathrm{~km}$ & \\
\hline
\end{tabular}

\section{Trajectory optimization results}

Usually during launch vehicle trajectory optimization, the payload mass to orbit is maximized. This approach is not a practical option in case of the SpaceLiner because this mass is fixed by top-level requirement to 50 passengers and their luggage. The range is defined by the geographical distance and not necessarily to be enlarged. Thus, the aim of the optimization task is to minimize the propellant load in the booster tank of the vehicle for the most demanding mission. The passenger stage has been kept unchanged during the optimization process. In order to fulfill the requirements in terms of final position reached and no violations of the constraints, the parameters to be optimized include: the initial heading, the duration of the phases, the propellant loading, the pitch control during the orbiter burn phase, the bank angle control during the cruise phase and the throttle setting of both the orbiter and the booster engines.

The ASTOS optimization process found a trajectory with a significant boost-phase propellant reduction of 55 Tons (-5.6\% of the total 986 Tons loading [12]) compared to the previous DLR optimization which was following the orthodrome in retrograde orientation. The groundtrack of this otherwise similar skipping trajectory is presented in black in Figure 4. The initial heading right after launch is far more northward (-8 degrees) than the great circle solution represented by the red track in Figure 4 . The increased range required is counterbalanced by the reduced negative effect of the Earth rotation. Note that the structural mass of the booster is not adapted during this optimization which would allow for an even slightly stronger improvement.

4. Pareto analysis between propellant and maximum heat flux

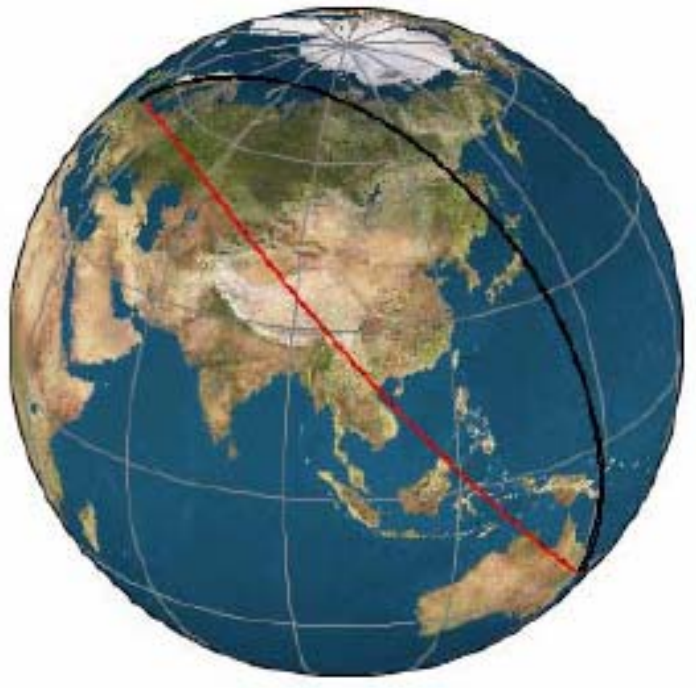

Figure 4: ASTOS "satellite view" of different possible groundtracks for reference mission Australia - Western Europe

The heat flux has a critical effect on the mission requirements: during the deep skips the high velocity at relatively dense atmosphere produces heat flux values that require heavy and complex thermal protection systems (TPS). On the other side the skips increase the range capability of the vehicle, thus reducing the propellant mass required for a fixed mission. An interesting analysis is achieved via a Pareto optimization comparing these two effects: the max heat flux and the total required propellant mass. The left boundary of the graph in Figure 5 represents the ASTOS optimization with minimum propellant consumption (also shown as the black line in Figure 4). 


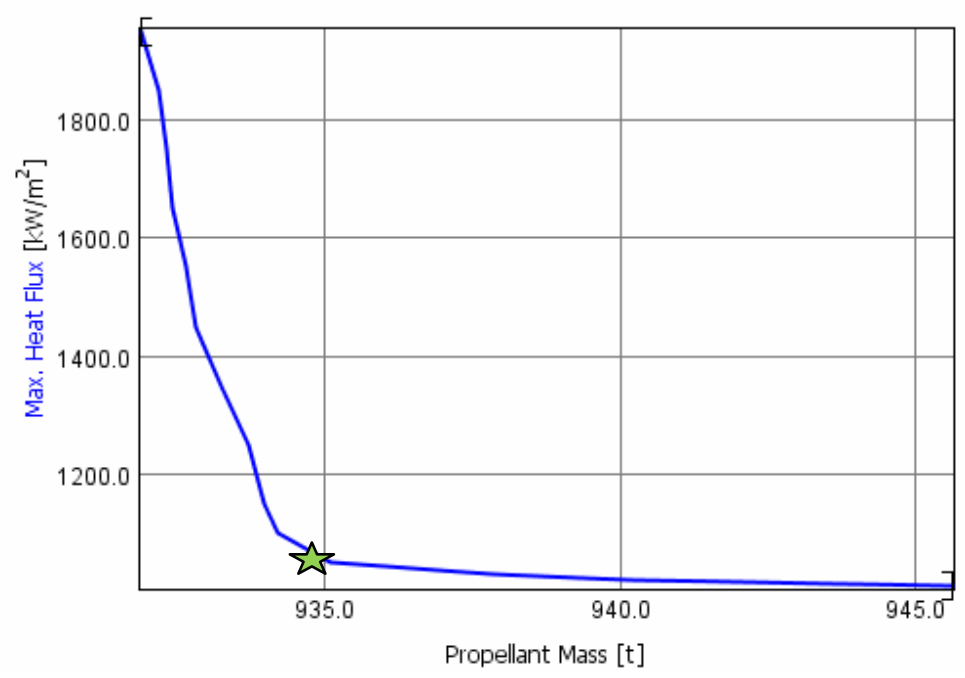

Figure 5: Pareto analysis between maximum heat flux and total SpaceLiner4 propellant mass

The maximum peak heat flux can be reduced from 2000 to $1000 \mathrm{~kW} / \mathrm{m}^{2}$, while the required total propellant mass moderately increases from 932 to 946 tons. The "no-skips" solution marked with a green star in Figure 5 identifies the best compromise: a strong reduction of the max heat flux (-46 \%) associated to no more than a slight increment of the propellant mass $(+0.3 \%)$.

The Figure 6 presents a comparison between the solution with lowest propellant mass (in black) and the "no-skips" solution (in green). The latter assures a smoother cruise phase, it requires 935 metric tons of propellant and present advantages also from the point of view of the passenger comfort: the load in the normal direction is not oscillating during the cruise phase.
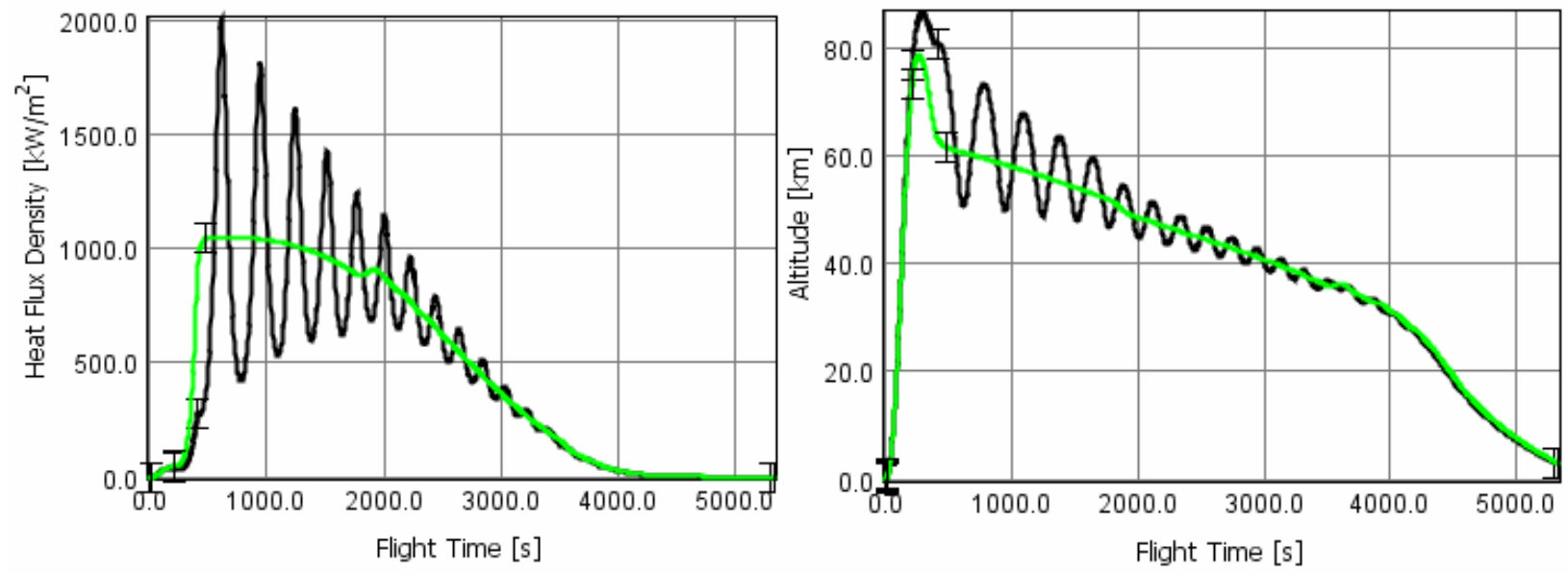

Figure 6: Heat flux and altitude vs. time (propellant minimized in black and no-skips in green)

The impact of the chosen flight strategy from minimum propellant consumption with skipping to a pareto-optimized hypersonic gliding on the trajectory parameters is quite interesting. The black curves in Figure 7 represent the flight with skipping and the green lines those with aerodynamic gliding. The latter is turning the optimum launch azimuth even further east- and northward. An impressive demonstration of the significant impact on the mechanical and thermal loads is shown in the right plot of Figure 7. With less than 4 tons of additional propellant a dramatic reduction of peak loads can be achieved. 

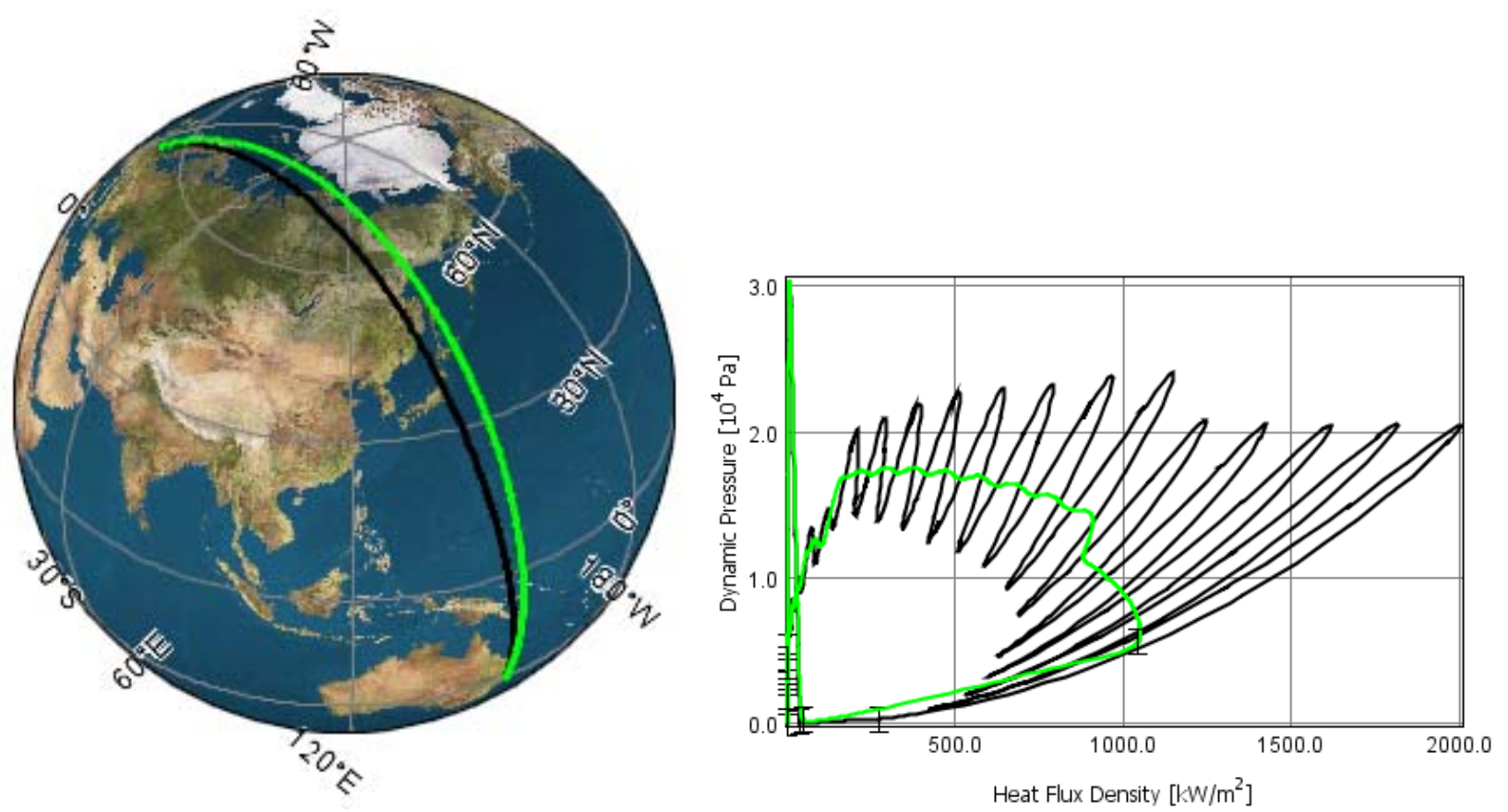

Figure 7: Groundtracks (left) and dynamic pressure vs. heat flux (right) for propellant minimized (in black) and no-skips (in green) trajectories

Figure 8 presents the minimum propellant skipping (in black) and pareto-optimized (in green) trajectories in a 3D map plot. The ground track is enriched with the altitude information that clearly shows a difference already during acceleration and final MECO altitude and subsequently the oscillation and gliding behavior during the "cruise" phase. The maximum altitude for the optimized long-haul distance flight is in both cases clearly below $100 \mathrm{~km}$.

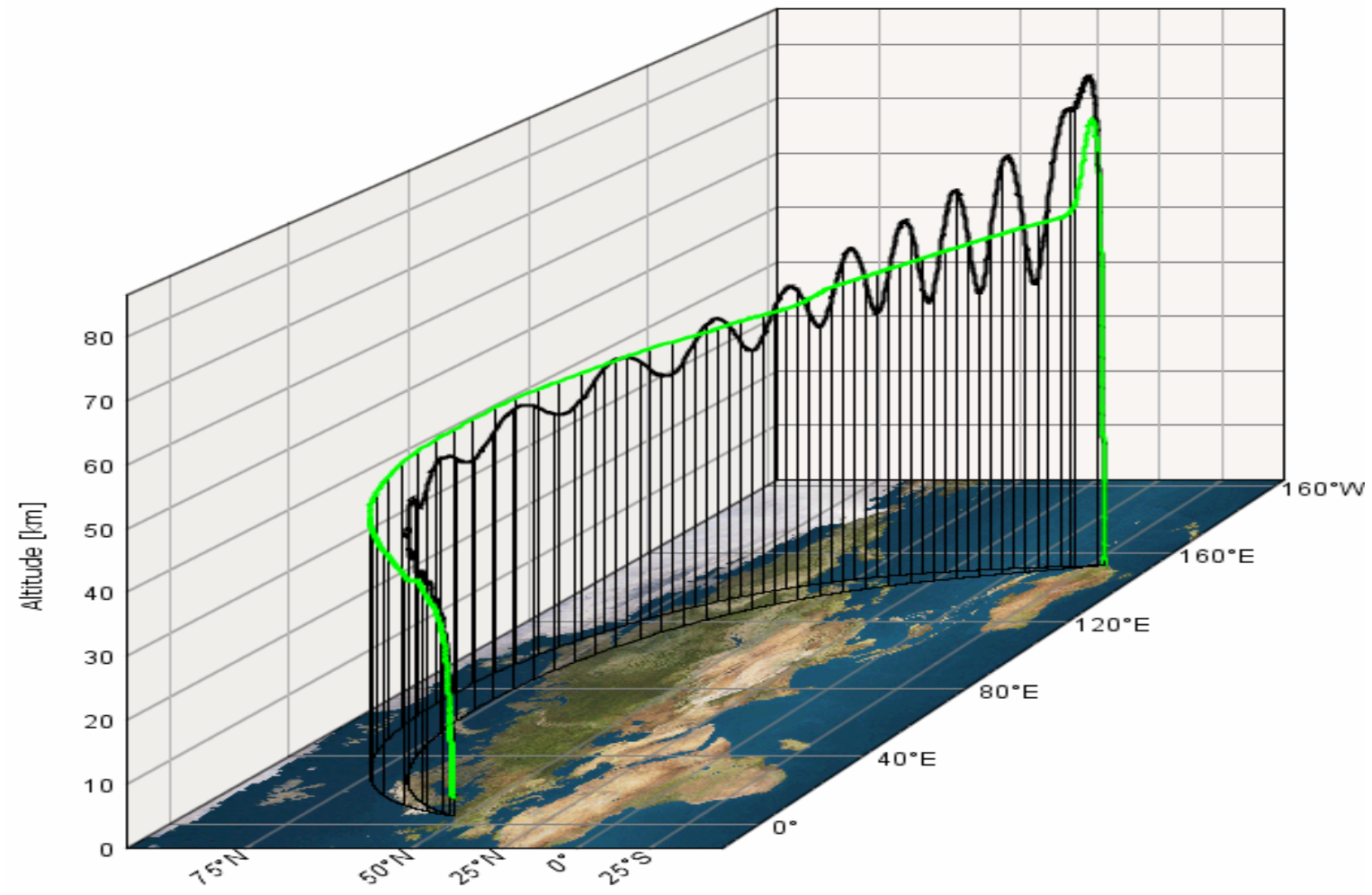

Figure 8: Optimized SpaceLiner reference trajectories of minimized propellant consumption (black) and pareto-optimized gliding (green) 
The north heading trajectory requires some hypersonic aerodynamic reorientation of the passenger stage in order to reach the final destination. The optimized bank angle and angle of attack history after MECO is presented for the non-skipping trajectory in Figure 9. The configuration is able to fly very close to the angle of attack at maximum $\mathrm{L} / \mathrm{D}$ considering small elevator deflections for trimming.

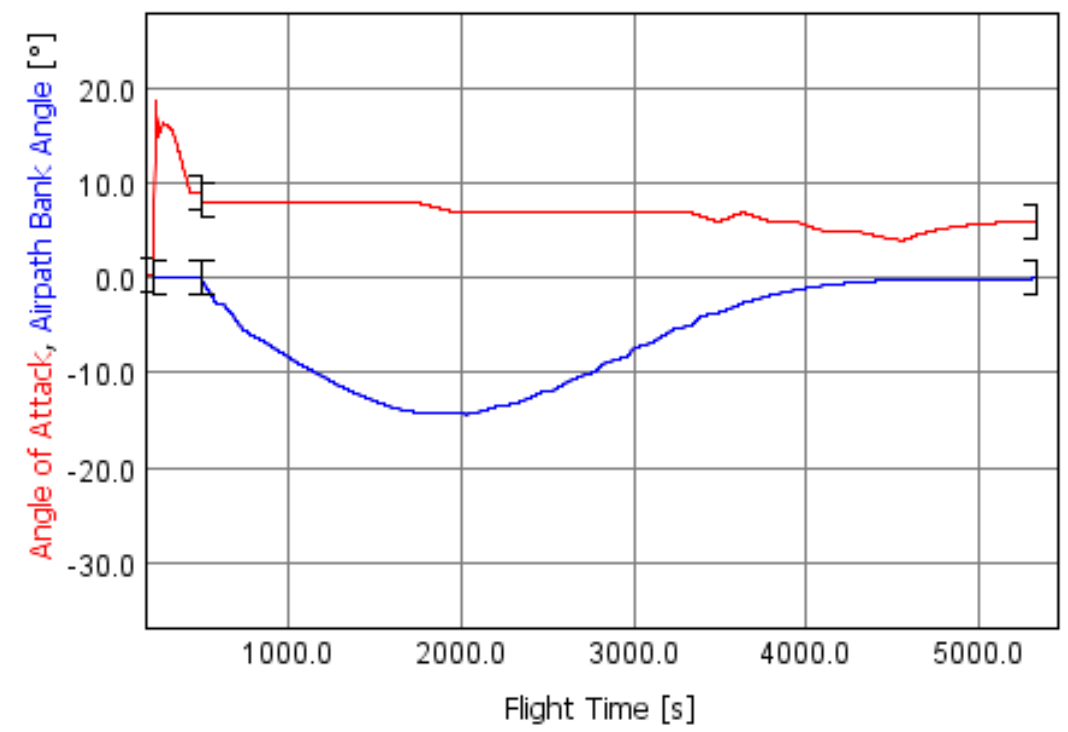

Figure 9: AoA and bank angle controls along full flight in pareto-optimized no-skip trajectory

\section{Thermal protection sizing}

A preliminary sizing of the SpaceLiner's TPS has been performed which demonstrates that the results from the Pareto optimization are more than of only theoretical value.

The TPS design is performed using fast engineering methods which allow investigating the full vehicle surface of the SpaceLiner along different trajectories. HOTSOSE is a fast code for preliminary flow analyses in hypersonics based on modified Newtonian surface inclination techniques. Friction drag is estimated for each panel with the classical analytical methods for compressible laminar or turbulent flow of van Driest and White-Christoph. The surface temperatures are calculated under assumption of an adiabatic wall in radiation equilibrium. Heat fluxes are determined by using the Fay-Ridell equation close to the stagnation point and the Zoby-Moss-Sutton approach further downstream. The real gas effects on gasdynamic and transport properties can be considered in the calculation for chemically reacting air in equilibrium [2]. A fully turbulent flow along the flight path has been assumed for the TPS dimensioning as a conservative assumption. HOTSOSE calculates the heat fluxes at each mesh point at selected flight conditions with Mach number, altitude, and angle of attack known from trajectory simulations. By this approach a heat flux profile over time is obtained for the complete vehicle surface. Using afterwards the tool TOP, the TPS thickness required at a certain mesh point on the vehicle can be determined, using the heat flux profile and the maximum acceptable temperature of the backstructure as input. TPS thickness optimization in TOP is based on a 1D thermal conduction model. The lightest possible TPS material for the mesh point is selected out of a user defined material data base.

Optimizing the material thickness for each of the thousands of mesh points on the vehicle would be excessively computational intensive. Additionally, this would yield a design without sufficient margin on the TPS thickness and which would be unpractical for manufacturing. Therefore, the vehicle surface is divided into a number of different regions. The point with the highest heat flux in a region is identified and subsequently TOP is used to determine the material and the TPS mass is calculated with a constant material thickness for the complete region.

The materials considered for the TPS analyses are:

- CMC- Alumina: Used for points with the highest heat fluxes. CMC (Ceramic Matrix Composite) can withstand temperatures up to $2000 \mathrm{~K}$. An alumina mat is chosen as a suitable insulator between the vehicle structure and the CMC top layer. 
- CMC- Alumina with water cooling: For points where the heatflux exceeds that which CMC can withstand, transpiration cooling using liquid water is foreseen [2, 17]. In FAST20XX this innovative method will soon be experimentally tested in DLR's arc heated facility [21].

- CRI (Conformable Reusable Insulation) chosen for regions with medium heat fluxes.

- AFRSI (Advanced Flexible Reusable Insulation): Also used on the Space Shuttle on the leeward (cool) side.

- $\quad$ FRSI (Flexible Reusable Insulation): Also used on the Space Shuttle on the leeward (cool) side.

The maximum acceptable temperatures for the passive TPS should be limited to approximately $1850 \mathrm{~K}$ to be compliant with the reusability requirement. The results of the TPS design for the different trajectories shown in Figure 6 through Figure 8 are given in Table 2. It can be seen that the trajectory without skips saves approximately 13 tons of total TPS mass. It's interesting to note that the maximum allowable structural temperature $\mathrm{T}_{\mathrm{b}}$ has additionally a strong influence on the passive TPS mass while the necessary water mass for cooling is only dependent of the chosen trajectory profile. The explanations for these phenomena are that the amount of water required is a function of the outer surface temperature and the maximum allowed structural temperature drives the TPS thickness. Letting the structure heat up to $400 \mathrm{~K}$ (for example when an aluminum structure is used), the total TPS mass for the no skips trajectory would be approximately 35 tons with $20.9 \mathrm{t}$ of that value for passive insulation. By using titanium or the polymer PEEK for example the structure could be allowed to heat up to $530 \mathrm{~K}$ or possibly even $600 \mathrm{~K}$. This would reduce the TPS mass to approximately 28 and 26.5 tons, respectively. Although the integrated heat load of the two trajectory options is very similar, the significant difference in total TPS mass is due to the cooling water only required at extreme heat peaks and the demand for heavier outer surface materials in case of higher temperatures.

Table 2: SpaceLiner4 TPS masses for two different trajectory options and different allowable structural temperatures

\begin{tabular}{|l|c|c|c|}
\cline { 2 - 4 } \multicolumn{1}{c|}{} & $\mathrm{T}_{\mathrm{b}}=400 \mathrm{~K}$ & $\mathrm{~T}_{\mathrm{b}}=530 \mathrm{~K}$ & $\mathrm{~T}_{\mathrm{b}}=600 \mathrm{~K}$ \\
\hline Minimum propellant trajectory $\left(\mathrm{m}_{\mathrm{p}}=932 \mathrm{t}\right)$ & & & \\
$\quad$ Passive TPS mass & $25858 \mathrm{~kg}$ & $19286 \mathrm{~kg}$ & $17581 \mathrm{~kg}$ \\
Coolant water mass & $21908 \mathrm{~kg}$ & $21908 \mathrm{~kg}$ & $21908 \mathrm{~kg}$ \\
Total TPS mass & $\mathbf{4 7 7 6 6 ~ \mathbf { ~ g g }}$ & $\mathbf{4 1 1 9 4} \mathbf{~ k g}$ & $\mathbf{3 9 4 8 9} \mathbf{~ k g}$ \\
\hline Pareto optimized gliding trajectory $\left(\mathrm{m}_{\mathrm{p}}=935 \mathrm{t}\right)$ & & & \\
$\quad$ Passive TPS mass & $20909 \mathrm{~kg}$ & $14157 \mathrm{~kg}$ & $12684 \mathrm{~kg}$ \\
$\quad$ Coolant water mass & $13752 \mathrm{~kg}$ & $13752 \mathrm{~kg}$ & $13752 \mathrm{~kg}$ \\
Total TPS mass & $\mathbf{3 4 6 6 1 ~} \mathbf{~ g g}$ & $\mathbf{2 7 9 0 8 ~} \mathbf{~ k g}$ & $\mathbf{2 6 4 3 6} \mathbf{~ k g}$ \\
\hline
\end{tabular}

Figure 10 shows the TPS materials used and their distribution on the surface of the SpaceLiner4 assuming the gliding flight. In the legend similar materials followed by different numbers indicate regions where the material thickness differs.
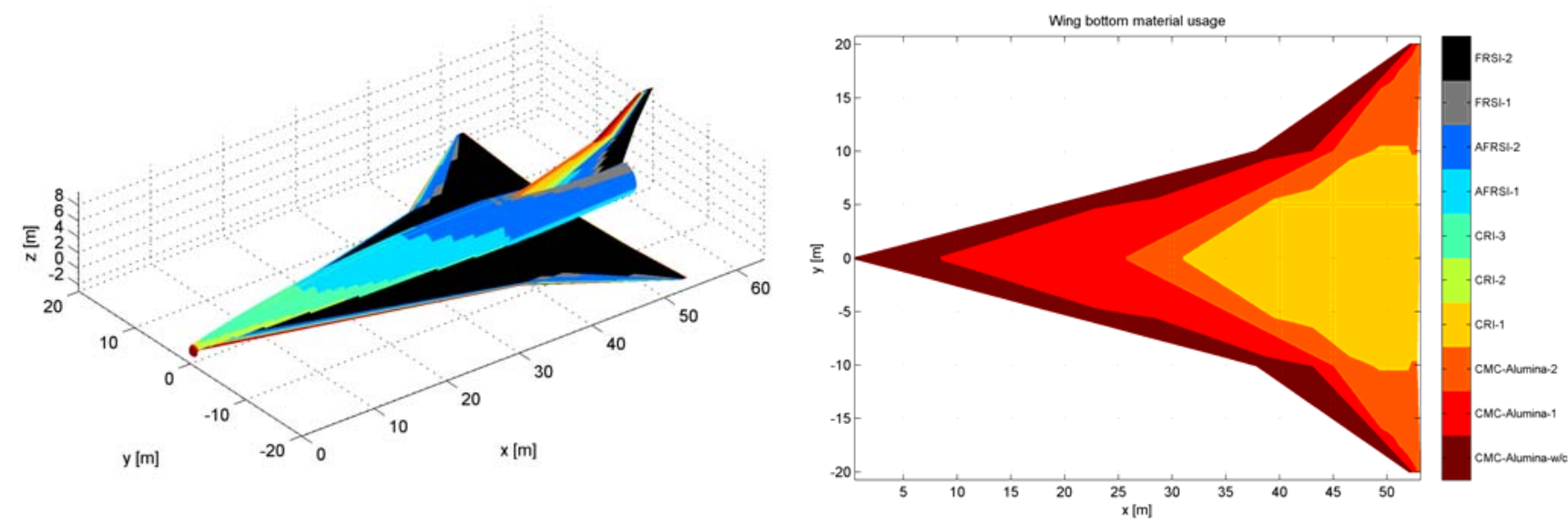

Figure 10: SpaceLiner4 TPS materials distribution, top side (left) and bottom side (right) 
Similar trade studies and a preliminary lay-out of the TPS have already been performed for the SpaceLiner7 deltawing configuration. Data are presented in [22] and in [18] also the impact on the structural sizing is discussed.

The system studies performed in FAST20XX demonstrate that the marginal propellant savings using a skipping trajectory are clearly outweighed by the extra TPS mass. Therefore, a hypersonic gliding flight without skips is chosen as the new SpaceLiner reference trajectory.

6. Cross-range capability during descent phase (from $40 \mathrm{~km}$ altitude)

The SpaceLiner might always be subject to the requirement of changing its trajectory relatively late in flight. Reasons could be a range reduction, either by low performing vehicle systems or by unknown atmospheric characteristics. Unfavorable weather conditions at the intended landing site might also require an adaptation of its trajectory. These well known situations from civil aviation are more challenging for the SpaceLiner because no active propulsion system is available onboard after MECO. Therefore, the capabilities of the vehicle have been assessed with ASTOS in reaching alternate acceptable landing sites. In order to do that the reference trajectory has been cut at $40 \mathrm{~km}$ altitude in two parts: between the "cruise" and the descent phase. The first part is kept unchanged while the bank angle is optimized during the descent in order to identify the boundary of the reachable area. Some examples are provided in Figure 11 where the initial point of the descent is at 72 degree North and 20 degree East.

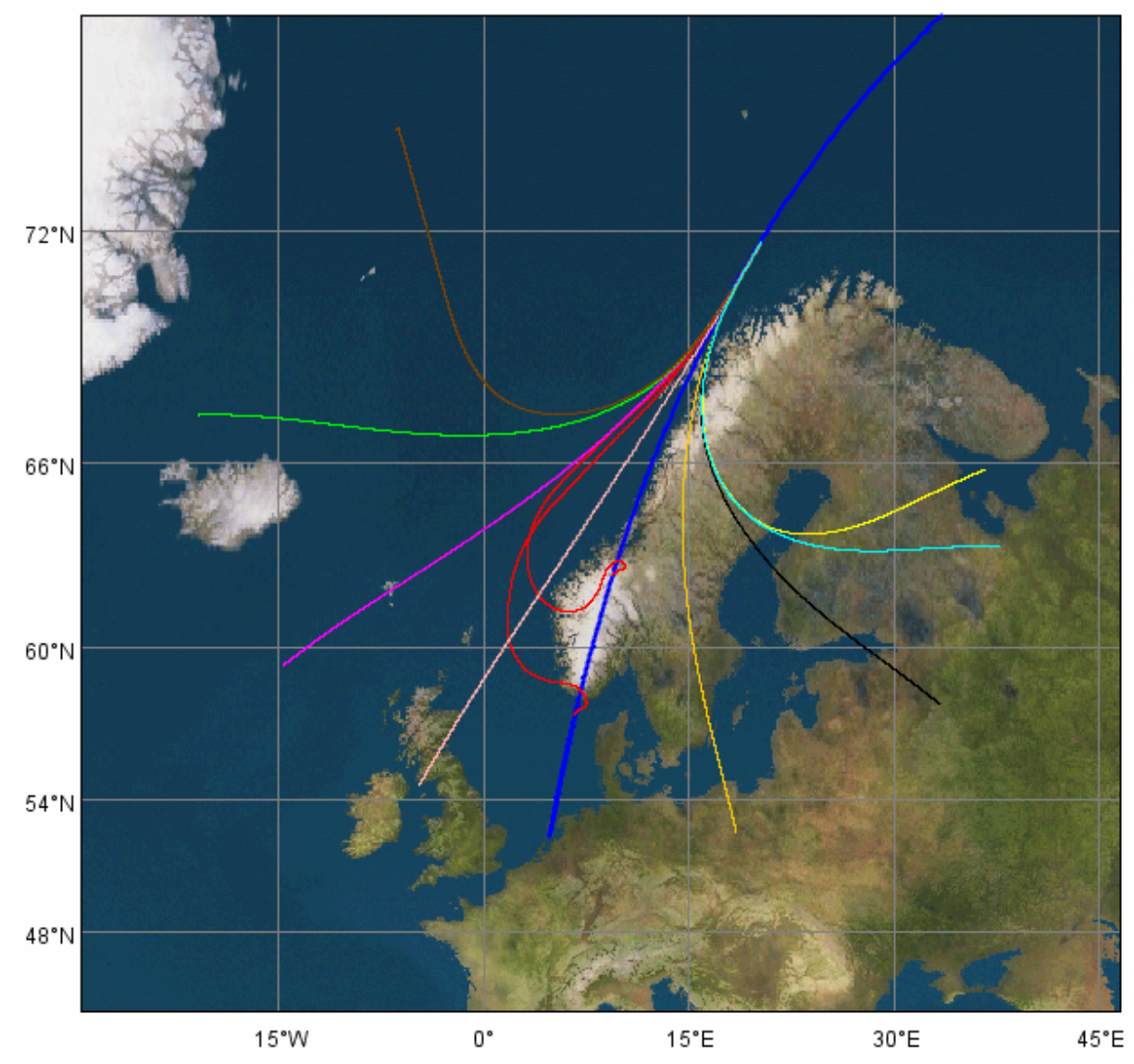

Figure 11: Range capability of the descent phase (from $40 \mathrm{~km}$ altitude)

It can be noted that the cross-range capability is impressive, around $2900 \mathrm{~km}$ between the point at the far most east and at the far most west. This would allow the SpaceLiner of reaching different landing fields spanning from Iceland, the northern UK, all of Scandinavia, northern Germany, the Baltic region, and western Russia with probably very diverse meteorological conditions. The reference trajectory (in blue in Figure 11) presents already the maximum down-range of the vehicle; the up-range results were computed in several steps. Figure 11 presents the results for final latitudes of 62.5, 57.5 (both shown in red), and 52.5 degree (reference). The distance between the shortest and the longest trajectory is $1160 \mathrm{~km}$. It would be possible to achieve a northern location only with a 360 
degree loop and while exceeding the constraint on the maximum normal load factor (compare Table 1!) of $1.5 \mathrm{~g}$. However, in emergency cases a maximum of $2.5 \mathrm{~g}$ are acceptable and at least in the example of the Europe-heading flight such turning might not be necessary because a sufficient number of alternate landing sites should be available.

\section{Aerodynamic Flap Selection Driven by Non-Nominal Flight Conditions}

Safe controllability of the vehicle in all flight conditions has to be assured including during abort cases. The Mach number range stretches from the hypersonics through the transonic regime to the low speed subsonic landing approach. An extensive study on the different geometrical options for the optimization of the hypersonic aerodynamic and aerothermodynamic characteristics of the SpaceLiner has been concluded at DLR. Progress most recently achieved in this area is presented in [19].

To define the wing flaps of the SpaceLiner, knowledge on the most extreme flight maneuvers is needed. This is currently assumed to be an abort scenario starting at the time of booster separation with the passenger stage's propulsion system inoperative. A re-entry trajectory for this case is simulated with the constraint of maximal allowed loads. The results show that angle of attacks of about 50 degrees need to be flown in the supersonic regime for a short time. Thus, for designing the size of the wing flaps such angles of attack need to be trimmable and maneuverable. At such high angle of attacks it is more beneficial when the center of gravity is moved backward. Several alternatives how to move the centre of gravity have been investigated and it is found that just dumping the remaining LOX is the best options.

A non-nominal 2.5g maneuver in subsonics and the nominal final approach before landing are found to be the other two dimensioning cases for the flap design. Angle of attack under these conditions is much smaller (below 20 degrees) but the resulting pitching moment is significantly stronger, requiring larger deflections.

The SpaceLiner4's trailing edge flaps have been preliminarily defined as elevons with two flaps on each wing for redundancy in case of blockage (Figure 12). The wing flaps are both sized with a $2.5 \mathrm{~m}$ chord and should be able to be deflected 20 degrees up- and 30 degrees downward in subsonic flight. In the FAST20XX study DEIMOS will perform dynamic flight control simulations, checking and refining the current lay-out.

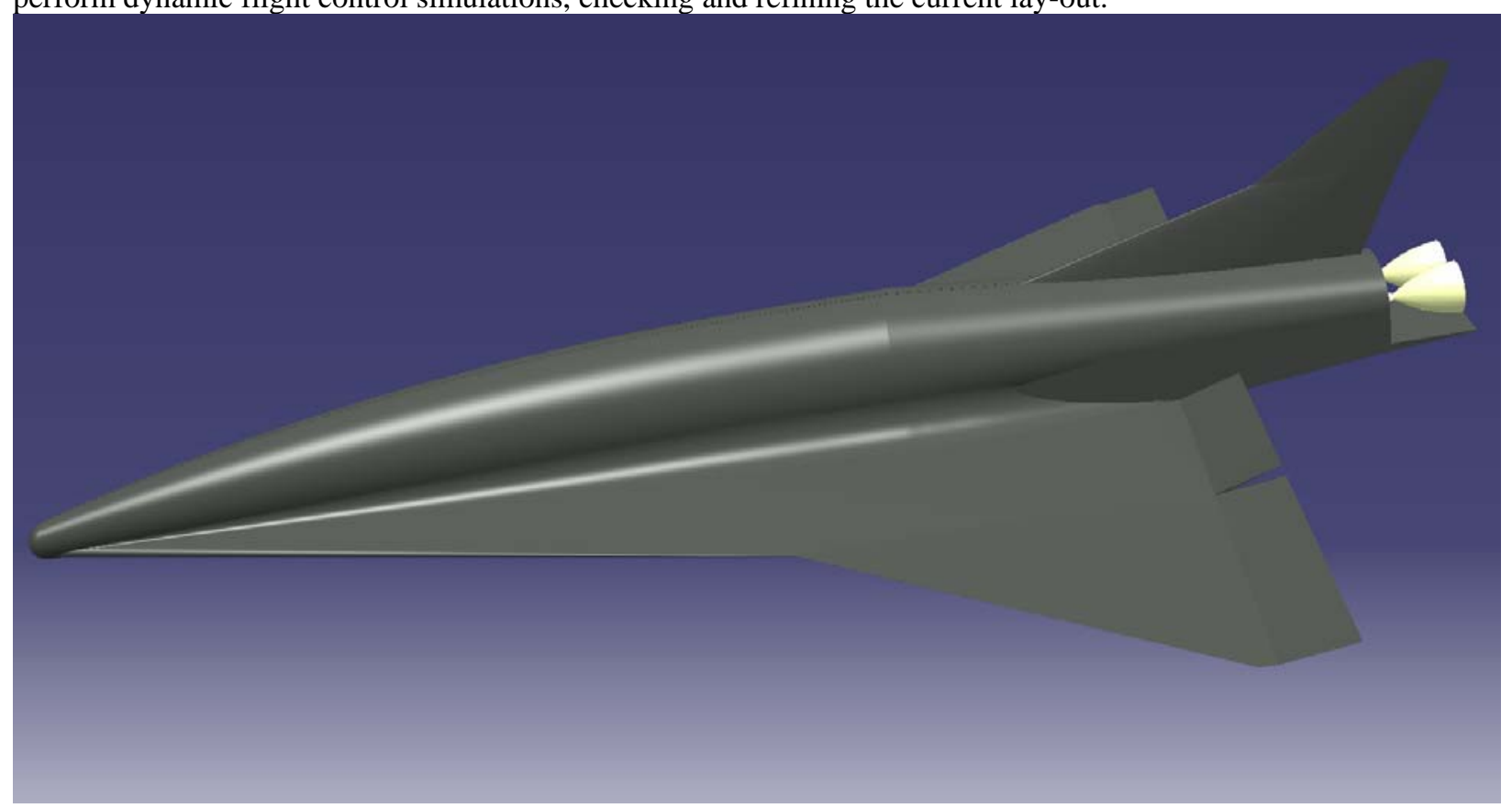

Figure 12: Elevon deflections shown at SpaceLiner4 CAD model

\section{E. Preparation of Next Development Steps}

All results obtained from the FAST20XX study and additional work performed at DLR under internal funding are influencing the next design step, the SpaceLiner7. This version will be based on much more detailed design of different subsystems and vehicle structures. An integrated interdisciplinary design process of the passenger stage 
will be necessary based on the ongoing configuration trade-offs. In [18] the structural sizing trade-offs are described. Further subsystems like e.g. propulsion and propellant feed system, power, and cabin environmental control will be traded and preliminarily sized. The impact of the system studies on the development of an updated aerodynamic configuration for the SpaceLiner7 will soon be published in [21].

Supported by FAST20XX activities, currently it is foreseen to conclude a Phase A study by mid 2013 on the SpaceLiner reference configuration and being prepared for reviews by the end of 2013.

\section{Conclusion}

A conceptual reusable winged rocket for very high-speed intercontinental passenger transport is proposed by DLR. Research on the vehicle is performed with support from the EU project FAST20XX. Assuming advanced but not exotic technologies, a vertically launched rocket powered two stage space vehicle is able to transport about 50 passengers over distances of up to $17000 \mathrm{~km}$ in about 1.5 hours.

The SpaceLiner concept, explicitly defined for ultrafast passenger transport, requires challenging technology. Its engine performance is intentionally less demanding than well known Space Shuttle technology which is now 30 years old. However, some key technologies and reliability have to be improved, to make the SpaceLiner vision economically viable.

The next iteration step of the SpaceLiner concept will be version 7 which will be based on more detailed design of different subsystems and vehicle structures than previous configurations. An integrated interdisciplinary design process of the passenger stage will be necessary based on the ongoing configuration trade-offs. The paper presents the latest investigation status on some major aspects.

The trajectory optimization program ASTOS has been used in FAST20XX for a sophisticated optimization of the SpaceLiner reference trajectory from Australia to West-Europe. A differently oriented, polar flight track enables a significant reduction in propellant mass. A newly generated hypersonic gliding trajectory allows for a dramatic reduction in maximum heat flux with only marginal increase in propellant loading. The preliminary sizing of the passive TPS run in parallel demonstrates that a much heavier thermal protection is to be used for a vehicle with skipping trajectory. This TPS mass increase far outweighs the propellant mass growth of the gliding flight. Thus, the new SpaceLiner reference trajectory drops skipping in nominal flight and switches to an optimized smooth hypersonic gliding.

The SpaceLiner4's trailing edge flaps have been preliminarily defined as elevons with two flaps on each wing for redundancy in case of blockage and their size is driven by non-nominal flight demands.

\section{Acknowledgements}

Part of this work was performed within the 'Future High-Altitude High-Speed Transport 20XX' project investigating high-speed transport. FAST20XX, coordinated by ESA-ESTEC, is supported by the EU within the 7th Framework Programme Theme7 Transport, Contract no.: ACP8-GA-2009-233816.

Further information on FAST20XX can be found on http://www.esa.int/fast20xx.

The authors gratefully acknowledge the contributions of Mrs. Uta Atanassov, Mr. Josef Klevanski, Ms. Carina Ludwig, Mr. Paul-Benjamin Eißmann, Mr. Paul Nizenkov, Mr. Dominik Neeb, Mr. Tobias Schwanekamp, Mr. Alexander Kopp, Mr. Daniel Keller, and Mr. Bryan Tong Minh to the preliminary design of the SpaceLiner.

\section{References}

1. Sippel, M., Klevanski, J., Steelant, J.: Comparative Study on Options for High-Speed Intercontinental Passenger Transports: Air-Breathing- vs. Rocket-Propelled, IAC-05-D2.4.09, October 2005

2. Sippel, M., Klevanski, J., van Foreest, A., Gülhan, A., Esser, B., Kuhn, M.: The SpaceLiner Concept and its Aerothermodynamic Challenges, $1^{\text {st }}$ ARA-Days, Arcachon July 2006 
3. Sippel, M.; Klevanski, J.: Preliminary Definition of the Supersonic and Hypersonic Airliner Configurations in LAPCAT, AIAA 2006-7984, $14^{\text {th }}$ Spaceplanes Conference, November 2006

4. van Foreest, A., Sippel, M., Klevanski, J., Gülhan, A., Esser, B.: Technical Background and Challenges of the SpaceLiner Concept, $7^{\text {th }}$ International Symposium on Launcher Technologies, Barcelona, Spain, April 2-5, 2007

5. Sippel, M.: Introducing the SpaceLiner Vision, $7^{\text {th }}$ International Symposium on Launcher Technologies, Barcelona, Spain, April 2-5, 2007

6. Sippel, M., van Foreest, A.: Latest Progress in Research on the SpaceLiner High-Speed Passenger Transportation Concept, IAC-07-D2.7.07, September 2007

7. van Foreest, A.; Sippel, M.: The Logistical Challenges of the SpaceLiner Concept, IAA $1^{\text {st }}$ Symposium on Private Human Access to Space, Arcachon May 28-30 2008

8. Sippel, M.: Promising roadmap alternatives for the SpaceLiner, Acta Astronautica, Vol. 66, Iss. 11-12, (2010)

9. “Brégier: On peut imaginer les avions fusées”, interview in Le Figaro, 24.9.2009

10. NN: SEVENTH FRAMEWORK PROGRAMME, THEME 7 [Transport, Aeronautics], Grant agreement for: Collaborative Project, small or medium scale focused research project1, Annex I - "Description of Work", Project acronym: FAST20XX, Project full title: Future high-Altitude high-Speed Transport 20XX, Grant agreement no.: 233816, 06 January 2009

11. Sippel, M.: SpaceLiner - a Visionary Concept of an Ultra Fast Passenger Transport under Investigation in FAST20XX, AIAA 2009-7439, $16^{\text {th }}$ AIAA/DLR/DGLR International Space Planes and Hypersonic Systems and Technologies Conference, Bremen 2009

12. Sippel, M., van Foreest, A.: SpaceLiner Rocket-Powered High-Speed Passenger Transportation Concept Evolving in FAST20XX, IAC-10-D2.4.06, September 2010

13. Kopp, A.; Lang, A.; Sippel, M.: Structural Load Case Definition for the SpaceLiner, Release 1 / 2-2011, SpaceLiner 4 Configuration, SART TN-024/2010, February 2011

14. Wiegand, A.: ASTOS User Manual. Unterkirnach, Germany: Astos Solutions GmbH. (2010)

15. Wiegand, A.: ASTOS Model Library. Unterkirnach, Germany: Astos Solutions GmbH. (2010)

16. Picone, J.M.; Hedin, A.E.; Drob, D.P.; Aikin, A.C.: NRL-MSISE-00 Empirical Model of the Atmosphere: Statistical Comparisons and Scientific Issues, J. Geophys. Res., doi:10.1029/2002JA009430, in press (2003)

17. Van Foreest, A. , Sippel, M.; Gülhan, A.; Esser, B.; Ambrosius, B.A.C.; Sudmeijer, K.: Transpiration Cooling Using Liquid Water, Journal of Thermophysics and Heat Transfer, Vol. 23, No. 4, October-December 2009

18. Kopp, A.; van Foreest, A., Sippel, Dalenbring, M.; Jarlas, R.: Investigation of Structure for the Hypersonic Transport System SpaceLiner, AIAA 2011-2373, $17^{\text {th }}$ AIAA International Space Planes and Hypersonic Systems and Technologies Conference, April 2011

19. Neeb, D., Schwanekamp, T., Gülhan, A.: Preliminary Aerodynamic Shape Optimization of the SpaceLiner by Means of Engineering Methods, AIAA 2011-2299, $17^{\text {th }}$ AIAA International Space Planes and Hypersonic Systems and Technologies Conference, April 2011

20. Mack, A.; Steelant, J.: FAST20XX: First Progress on European Future High-Altitude High-Speed Transport, AIAA 2011-2337, $17^{\text {th }}$ AIAA International Space Planes and Hypersonic Systems and Technologies Conference, April 2011

21. Sippel, M.; van Foreest, A.; Dietlein, I.; Schwanekamp, T.; Kopp, A.: System Analyses Driving Improved Aerothermodynamic Lay-out of the SpaceLiner Configuration, ESA-SP692, to be published May 2011

22. Tong Minh, B.: Design of the SpaceLiner Thermal Protection System, SART TN-002/2011, 2011

Further updated information concerning the SART space transportation concepts is available at: http://www.dlr.de/SART 